\title{
Standards formation and the implications for HRD
}

Heather Short ${ }^{1}$, Valerie Anderson ${ }^{2}$

1. Faculty of Business and Law, University of Portsmouth, UK

2. Faculty of Business and Law, University of Portsmouth, UK

Corresponding author:

Dr. Valerie Anderson, Reader in Human Resource Development, University of

Portsmouth. T: +44(0)2392844029. E: valerie.anderson@ port.ac.uk

\section{$\underline{\text { Author notes }}$}

1. Both authors contributed fully and in a collaborative way to the development of this paper. Dr Heather Short was responsible for data collection and data analysis; Dr Valerie Anderson was responsible for the theorization and conceptual features of the paper.

2. This work was supported by a University Forum for Human Resource Development (UFHRD) Research Honorarium awarded in 2018 


\title{
Standards formation and the implications for HRD
}

\begin{abstract}
Purpose: This research explores the implications of national and international standards for Human Resource Development (HRD) practice. It focuses on the experiences, perceptions and learning of those involved in the social construction of standards and standardisation processes.
\end{abstract}

Design/methodology/approach: The research is grounded in institutional and organisational excellence theories and adopts a qualitative approach, based in social constructivism. Thematic analysis of the data obtained from thirteen semi-structured interviews leads to a discussion of awareness of standards, standards adoption including constraints and impact of standards.

Findings: Findings indicate that that there has been a disconnect between the potential impact of British Standards Institute (BSI) Human Resource (HR) standards and what has occurred in practice, with little awareness of the BSI standards among practitioners.

Research limitations/implications: This paper identifies an absence of institutional isomorphism in the HR arena and highlights the potential for a 'standards-practice' gap where HR standards formation processes are perceived as detracting from flexibility and innovativeness in organisational practice.

Originality/value: This paper contributes a new perspective of the implications of HR standards formation from the perspective of those involved and further contributes to the wider theorisation of standards in the HRD field.

Key Words: standards; standardisation; BSI; HRD

\section{Standards formation and the implications for HRD}

\section{Introduction}

This paper examines the implications of British Standards Institute (BSI) HR standards for HRD practices. It focus is on standards defined as an 'agreed, repeatable way of doing something' (British Standards Institute [BSI], 2018). Standards are increasingly dominant in organisational life and management practice. Governments and intergovernmental organisations may be involved in setting or enforcing standards (Yates and Murphy, 2019) but non-governmental, consensus-based processes dominate the field. Since the turn of the 20th century, many national standardisation organisations, such as the BSI and 
the American National Standards Institute (ANSI) have formulated and promoted standards for use in organsations (Wong, Anderson and Bond, 2019). The purpose of the globally influential International Organization for Standardization (ISO) is to create standards that are intended to be adopted internationally. This organisation comprises national standard-setting bodies of over 160 countries (Yates and Murphy, 2019).

Initially, standardisation organisations focused on the creation of rules for the design of industrial products to enable interoperability and minimum thresholds of product or service quality. More recently, the remit of standardisation has expanded to include organisationwide management systems and practices (Corbett and Yeung, 2008). These include ISO 14001 environmental management systems standard and ISO 9001 Quality Management Systems standard (Heras-Saizarbitoria and Boiral, 2013). In addition, standardisation bodies, such as ISO, have further widened their scope to develop standards across professional or occupational fields such as Asset Management [TC251]; Risk Management [TC262]; Sustainable Finance [TC 322]; Education and Learning Services [TC 232]; Occupational Health and Safety Management [TC283] and Human Resource Management [TC260] (https://www.iso.org/technical-committees.html).

The core of the work of standardisation organisations is undertaken by technical committees established to reach consensus on the documents which comprise 'the standards'. This is characterised by Yates and Murphy (2019) as a technocratic process underpinning the development, publication and application of guidelines, specifications and rules. The process requires the consensus of relevant expert stakeholders to ensure compatibility, and consistency (Wong, et al, 2019). Those involved tend to be representatives of public and private sector organisations; employer bodies; technical experts, 'think tanks'; professional and scholarly associations and worker representation organisations (Anderson, 2017). 
Although the Investors in People Award scheme has been prominent in the HRD field for over twenty-five years (Murphy \& Garavan, 2009), standardisation processes in the HR field by organisations such as ISO, ANSI, and BSI have been initiated since 2009. The process was commenced in the USA (Jacobs, 2013) and an ISO Technical Committee to develop standards in HRM was initiated in 2011. The published purpose of the ISO Technical committee (TC260) focused on HRM standards and standardisation is to "facilitate international business by providing guidance on professional practice standards and improve internal processes", the aim being that "HR practices should become comparable and consistent to enable a transparent benchmarking and contribute to professionalization of human resource management" (ISO, n.d.). In addition, a BSI national-level Technical Committee was established in 2011 (Wong, 2013). The purpose of the BSI committee is to prepare, publish and review HR standards (referred to by this committee as Human Capital standards) and to enable the UK to input to the ISO Technical Committee (BSI, 2020).

Alongside these developments considerable proliferation has occurred in the development of a range of alternative market-led HR awards and standards. In addition to the UK Investors in People (IiP) award, 'kitemarks' such as the Healthy Working Lives Award; the Best Companies Award; The Great Place to Work Scheme, and the Top Employers Award have emerged (Mulvie, 2019). This suggests a trend towards standards and standardisation in the HR field.

Although the focus of this paper is on the professional area of HRD, standards formation bodies, such as the BSI, combine standardisation processes for HRM and HRD. Therefore, the study reported here examines standards development processes for the field of HR as a whole and the implications for HRD practice, of the following three BSI standards: BS76000, Human Resource. Valuing People. Management System. Requirements and Guidance (published in 2015); BS76005 Valuing People Through Diversity and Inclusion: 
Code of Practice for Organizations, and PD76006 Guide to learning and development (both published in 2017) (BSI, 2017a; BSI, 2017b; BSI, 2015). (See Appendix A).

In focusing on these BSI standards this paper extends knowledge generated by studies of the Investors in People award (cf. Alberga, Tyson, and Parsons, 1997; Bell, Taylor, and Thorpe, 2002; Bourne, et al. 2008 ; Gloster, et al. 2010) and adds to knowledge arising from studies of standardisation processes in other organisational and sector-wide contexts (Botzem and Dobusch, 2012; Brunsson, Rasche, and Seidl, 2012; Lahiff, et al., 2019). It provides the foundation for a much needed theorisation of the influence of standards formation in professional fields such as HRD.

Two research questions form the basis for this paper:

1. How do contextual conditions, prior knowledge, and experience of those involved in standardisation, affect HR standards formation processes?

2. What issues do those involved in standards development identify concerning the implementation and adoption of HR standards?

The paper begins by examining and problematising existing approaches that explain the growth of standardisation in work organisations. The next section outlines and explains the social constructivist research design, procedures and analytical stance underpinning the study. The outcomes of the thematic analytical process are then described. This is followd by a discussion of the findings and consideration of the implications for theory and practice.

\section{Theorising standards}

At an organisational level, HR and HRD standards and standardisation have primarily emerged as a feature of the growth and prevalence of quality management and quality assurance systems (Mulvie, 2019). As indicated already, early standards development in fields outside of HR were directed at technical and manufacturing specifications and requirements to enable design effectiveness, process efficiency and product quality assurance. 
Over time standards extended to include organisation-wide management systems and practices, often referred to as meta-standards (Corbett and Yeung, 2008).

The increasing prevalence of organisation-wide management standards can be understood in terms of organisational excellence theory (de Waal, 2013). This suggests that different systemic factors contribute to the achievement of sustained excellence and high levels of organisational performance (Mi Dahlgaard-Park and Dahlgaard, 2007). Organisational excellence theory draws on open systems theory. Its development over time represents a fusion between Western (primarily North American) and Eastern (Japanese) assumptions about the integrative features of organisational and competitive systems (Scott, 2003). Different operational and people-related factors and organisational characteristics feature in models and frameworks associated with organisational excellence. These include organisational design, strategy, technology, leadership, culture, external orientation, operational process, and people development. With specific relevance to HRD, de Waal (2013) identifies dimensions from frameworks associated with organisational excellence that include encouragement of a learning culture and developing people to be resilient and flexible. In addition, organisational excellence theory focuses on core competencies, and alignment with company values and direction. Such practices also feature as components identified in high performance work systems (HPWS) theories (Barney, Wright and Ketchen, 2001; Clardy, 2008). However, across the range of different models and frameworks developed from the principles of both organisational excellence theory, and HPWS theories, there is no consensus on the specification of HR or HRD practices that guarantee sustained organisational performance.

These theories take a functionalist and normative approach directed at efficiency improvements. Critics argue that claims that models of organisational excellence have a universal applicability are problematic (Brunsson et al., 2012). First, different national, 
cultural and organisational contextual factors have substantial effects on the systemic features required to generate organisational performance (Mi Dahlgaard and Dahlgaard, 2007).

Second, organisational excellence theory underestimates the effect of different organisational cultures and leadership styles. In organisations where an organisational culture that emphasises rational-measurement processes is dominant, for example, it is likely that concern for HRD orientated features of excellent practice will be given less attention than dimensions such as the simplification and improvement of processes, measurement, and continuous process optimisation (de Waal, 2013; Mi Dahlgaard and Dahlgaard, 2007). Third, organisational excellence theory fails to account for other risk and decision factors that affect performance (Goetsch and Davies, 2014). For example, within the HRD field, studies suggest a reluctance to harmonise organisational-level training and continuous development processes as this is understood as compromising organisational flexibility, change readiness, innovativeness and organisational differentiation (Anderson, 2017; Lahiff et al., 2019; Short and Harris, 2017; Smith et al., 2014).

In the standards literature, in response to these critiques, a distinction has been proposed (see, for example, Anderson, 2017) between traditional, compliance-based 'rules' and procedures and an approach to standards and standardisation referred to as 'principlesbased'. This distinction suggests that traditional rules-based standards are appropriate for technical and product design areas. They contain detailed and comprehensive process requirements as the basis for audit of practices to ensure consistency and compliance (Botzum and Dobusch, 2012). For other professional areas, such as accounting and HR, advocates of a principles-based approach argue that standards might comprise a smaller number of principles to focus on values and broader outcomes. This approach, it is argued, provides a more meaningful basis for judgement and responsiveness in professional practice (Agoglia et al., 2011; Polacek et al., 2012). 
An alternative explanation of the increasing prevalence of standards in organisational and social life is provided through institutional theory (DiMaggio and Powell, 1991; Scott, 2008). Institutional theory also builds on an open systems perspective. However, it adopts a more critical stance towards increasing patterns of harmonisation of management work processes, belief systems and rules. Institutional theory considers competitive environmental factors to be an important influence on standardisation in organisations (DiMaggio and Powell, 1991; Scott, 2008). It focuses on the way that the competitive environment determines structural, procedural and cultural-cognitive features of work organisation. Institutional theory critiques harmonised or standardised processes as evidence of institutional isomorphism and as a feature of managerial discourse that privileges hierarchical structures of authority in organisations.

Institutional theory conceptualises three forms of isomorphism (coercive, normative and mimetic) that lead organisations to increasingly resemble each other and to engage in practices that reduce professional discretion (Murphy and Garavan, 2009; Ponnert and Svensson, 2016). From this perspective, the increasing role of standards bodies such as BSI and ISO in formulating standards for HR practice can be understood as a form of normative isomorphism. In addition, the concept of mimetic isomorphism, which occurs when organisations copy or imitate other successful organisation's 'best practices' (Chapman et al., 2018) is relevant to the proliferation of market-driven 'people-focused' employer awards, such as the Healthy Working Lives Award and the Best Companies Award.

However, in the HR field the assessment criteria for the various market-orientated awards suggest variety rather than harmonisation of meanings and priorities. In addition, evaluations of the impact of the Investors in People award indicate concerns in the HR field about limitations on organisational flexibility and differentiation (Gloster et al., 2010). A further lack of consensus is evident about which HR processes are relevant for performance 
outcomes across different sizes and types of organisations and across different geographical locations (Anderson, 2017). In short, institutional theory cannot account for situations when attempts to bring about uniformity through formalised standards are unsuccessful (Brunsson et al., 2012).

This problem draws attention to the nature of HRD practice. The relevance of standards and standardisation may be problematic in the HRD field. In order for standardised rules or guidance to have legitimacy, consensual agreement between stakeholders who will be affected by them is necessary (Brunsson et al., 2012). Organisational excellence theory assumes that the benefits of standardisation are self-evident. Institutional theory assumes that they are an inexorable consequence of isomorphism. Both theories underestimate the importance of socially interactive processes within fields of practice to create, sustain and implement standards. This study provides the opportunity to overcome the problems of institutional theory and organisational excellence theory in explaining the influence of HRD standardisation processes.

A social constructivist stance is taken in this study to enable exploration of formally and informally enacted standards formation processes and procedures within contextualised situations. Technical committees represent a negotiated form of social order and the influence of standards that they develop will be interrelated with wider understanding and sensemaking of committee members. The study focuses on the contextual conditions that affect perceptions, meaning making and experiences of those involved in standards formation and considers their influence for HRD practice.

\section{Methodology}

In line with the social constructivist approach, a qualitative approach was adopted, based on interpretivist theoretical and methodological principles. This section details the population and sample, the data collection and fieldwork and the data analysis. 


\section{Population and Sample}

The research population comprised all those who have been involved in formal HR standardisation processes or have attended a launch or publicity event associated with any of the standards being investigated. Details of this population were obtained through involvement of one of the authors with BSI committees. This is estimated to be approximately 100 people.

All members of the population were contacted by email, explaining the purpose and format of the research and asking whether they would be willing or able to take part in the research. In order to obtain sufficient numbers of research participants, a second email was sent to all non-respondents which eventually led to fifteen possible participants. Research participants were interviewed in the chronological order in which they replied to the emails. Following two pilot interviews, additional interviews were undertaken until data saturation was reached. Thirteen interviews were undertaken in total and the interviewees are referred to by incremental alphanumerics in the Findings section below, that is, IV1, IV2 and so on. Table 1 gives details of the interviewees' experience of work in general, the industry (ies) / sector(s) in which they have worked and the time period, and their experience with standards in particular, namely the length of time that they had been involved with standards, on which particular standards they had worked and the standards events which they had attended. It should be noted that some interviewees, particularly IV1, IV3 and IV7 have been involved in standards within organisations other than BSI and ISO, for example in large multinational concerns.

\section{Insert Table 1 about here.}

The size of the population was limited due to the small number of people involved in HR standardisation processes and the data which are obtained from such a small sample cannot claim to be representative of what happens generally (Rodham, 1998; 
Saunders et al., 2016). However, this research sought to generate contextual findings that might be transferable to different situations (Sayer, 1984; Watson, 2001).

\section{Data Collection and Fieldwork}

A semi-structured interview method was used in order to produce data that could address the research questions while providing opportunities to explore interviewees' responses (Savin-Baden and Major, 2013). The interviews aimed to produce in-depth data, focus on specific topics, and be insightful through perceived causal interferences (Yin, 2016).

Due to the wide geographic dispersal of the interviewees, these were conducted via the telephone or Skype, depending on the interviewee's preference. Interviews lasted between 45 and 60 minutes and used an interview protocol which permitted flexibility to vary the order of questions and to include additional questions, depending upon interviewees' responses (Bell et al., 2019). This allowed interviewees some freedom to both "express their perspectives" (Savin-Baden and Major, 2013, p359) and clarify their understanding of questions, within a framework which encompassed both the subject area and time restrictions (Savin-Baden and Major, 2013; Yin, 2016). The interviews were audio-recorded and transcribed.

Data Analysis

Resultant data were analysed thematically with the aid of NVivo 12 software. Thematic analysis was chosen because of its systematic approach which concentrates on commonalities, relationships and differences (Braun and Clarke, 2006; Gibson and Brown, 2009). In recognising the need for research participants to articulate their perceptions and experiences freely, it does not use pre-defined categories to analyse data, but derives categories of meaning, and relationships between those categories, from the data itself through coding, that is a process of inductive reasoning, in order to explain the processes being researched (Lofland and Lofland, 1995). 
Thematic analysis involved the two authors engaging in the six-step thematic analytical process outlined by Braun and Clarke (2006). Firstly, the data were transcribed verbatim, which produced 208 pages of double-spaced typed text. The authors then read and re-read the transcripts to familiarise themselves with the content. Secondly, the data were coded using general labels across the dataset using NVivo 12. This was undertaken separately by each of the authors and open coding generated 68 initial open code labels. These open codes included areas such as need for standards, interest in standards, awareness of standards and advantages of using standards.

Next, the authors engaged in analytical face-to-face conversations to identify areas of coding agreement and variance and to establish empirical dimensions and potential themes as well as possible relationships between themes and potential analytical outcomes (Gioia et al., 2013). This process led to agreement on the identification of 15 empirical dimensions and 6 potential themes. One further empirical dimension (The nature of HR practice) was identified during this process.

The data were then re-analysed and, in a recursive way, the themes and empirical dimensions were reviewed, refined, renamed as appropriate, and defined. The empirical dimensions included areas such as personal interest / motivations, stakeholder involvement, constraints on adopting standards, and the influence on personal practice. The resultant themes were pathways to involvement, nature of standards, standards development, awareness of standards, standards adoption, and impact of HR standards. The map which was developed from the thematic analysis of the data is shown in Table 2 and the resultant themes are the basis for the discussion of the findings.

Insert Table 2 around here

\section{Findings}


This section is structured around the themes shown in Table 2 which have arisen from analysis of data from the interviewees, details of whom, including their experience regarding standards, is given in Table 1 . This section is structured to initially clarify what the interviewees understand by the word 'standards' before showing how they became involved in standards in general and the BSI standards development process in particular. Next the interviewees' views on the awareness of BSI HR standards within organisations is explored, including how this affects standards adoption, with particular examination of contraints to this. Finally the interviewees' opinions of the impact of HR standards is considered.

Taken as a whole the main finding of the research is that BSI HR standards have, so far, had little impact. The findings indicate that this is largely due to widespread lack of awareness of the standards, mostly due to little communication of them by BSI. Additionally, although interviewees all asserted that there was a need for standards, they also felt that many organisations did not see this need and that even those who did see a need, were reluctant to buy BSI standards as there was little evidence of advantages gained from adopting them. Nevertheless, some interviewees thought that generally more time was needed for standards to be widely adopted. There was also discussion of what could be done to increase awareness of the standards and who should take responsibility for this. These points are examined in more detail below.

\section{Nature of standards}

The first part of each interview included trying to exploring what each research participant understood by the term 'standard'. The need for a clarification of the characteristics of standards was widely recognised by the interviewees who made comments such as "There isn't a high recognition of what the standards are and what they can do" (IV11). There was much agreement between the interviewees regarding what a standard is, for example "A standard is an essential guideline to help companies do the minimum 
required, to do the right thing... It's a roadmap" (IV8), "kind of like route maps" (IV11) and "they set a benchmark... an articulation of what 'good' looks like" (IV3). Nevertheless there were strong feelings that standards should not be prescriptive, but rather that they should ".. help people who may not know much about a topic... help you navigate into a professional area. It's not a one size that fits all."(IV3)

Many interviewees commented that standards seemed to be perceived as relating to production and technical areas and so HR “... is not what people traditionally first think when they think of standards....it's not the area where they would expect to find them" (IV11). Some participants had doubts about the applicability of standards to HRD with comments such as “... with learning and development, because it's directly related to the performance of people, there are so many other factors that it's impossible to say: 'if you impose this standard then you will be more profitable or it will make you a better company' "“ (IV1) and "where are you going to get innovation if everyone is doing the same thing...? learning and development particularly is one where over-standardisation would prevent creativity" (IV10).

Pathways to involvement

Initial interview questions aimed to ascertain how the research participants had become involved in HR standards; some information about this is given in Table 1. Mostly involvement had arisen from specific job roles with a few of them having been involved in standards for considerable amounts of time, although these were not BSI or ISO standards initially, for example IV1 claimed to have worked with L\&D standards for 24 years: "I was one of those people who set up... an institute of IT Training and that was the first test to provide some sort of quality assessment in a field where there was no quality control". Similarly IV7 had been involved with standards for 18 years, this originally being with "NVQ's... developing and 
writing assessment material and the competence detail [for them] ... then as an internal verifier... and then as an IiP adviser."

Several interviewees stated that they had little knowledge of standards until their job required them to develop awareness in this area, with IV13 saying "I was aware of ISO just because of the ubiquity of the 9001 standards for quality management, but I didn't know much" and IV4 and IV8 making similar comments. IV11, like some other interviewees was unaware that there were BSI and ISO standards relating to HR, commenting that "I probably would have been on the same page as lots of other people who have a vague recognition of ISO and what it was doing relating to quality, but... more sort of technical mechanical context"; this was a view echoed by IV2.

Others found standards seemingly by accident and then found that these helped them develop their careers and so became enthusiastic about them, for example, "I didn't really know what I was doing as there were no standards that I was aware of... the minute I cottoned on that there was something to help me organise things, I latched on to them" (IV9).

Standards development

Although most of the interviewees had, to varying extents, been involved in the development of HR standards, some indicated that they knew little about standards until this involvement: "I didn't know much beyond the fact that [ISO9001] seemed to be plastered everywhere and was about quality" (IV13). Others, however, had considerable experience of standards, although some stressed that these were "Non-HR standards - in the laboratory we were testing to standards ... that's what 9001 is about ....do it well and do it consistently well..."(IV7).

Despite there being widespread acknowledgement of the need for standards in many areas - "there is, as you know, a tendency for organisations to want to seek best practice" (IV10), - the feeling that it would be difficult to develop standards for HR persisted "because standards to date were technical standards" (IV13). That interviewee continued later "I was 
intrigued as to how they could standardise HRM so there was that intellectual curiosity, but at a national level I was very keen to see whether it was possible to explore human capital standards - principles-based standards - where the standard didn't actually prescribe every last action but instead provided a kind of framework"(IV13). Another participant said "the area of HR is more of an art that a science. It's easy in terms of production: you're measuring cost, wastage, number of widgets produced. I'm not convinced that systematically all of the same - and the right - measures are in place for HR" (IV7).

It became apparent that, before their involvement in developing standards, many of the participants had little understanding of not only what standards were, but also what the development of them involved, with comments including "we knew how standards work, but we didn't know how they were developed or promoted so we only realised [ what was involved] after we started the process of developing standards... ... and the ramifications of it” (IV6). There were comments about the standards development process having "inherent challenges, practical challenges" (IV8) and "I thought that there would be a more integrated approach to standardisation" (IV6). It was emphasised that standards development needs "people prepared to invest the time in doing that" (IV1) and that "you have to keep at it... it's quite a hard slog"(IV3). Nevertheless there was much commitment to continue working on developing HR standards with comments such as "It's the principles and values around this standard that I absolutely endorse"(IV2).

There was discussion by some interviewees concerning who should be on the development committees and standards boards as they believed that members of the committees and boards would take information about the standards back to their organisations, as the interviewees themselves did. One explained "we could get more people involved in drafting so they can see the level of detail that goes into the discussions" (IV5). A few interviewees voiced concerns about the current memberships of the committees with 
one commenting "There are academics on standards boards, but little representation of those who need the standards most. We need greater input from SMEs"(IV8). Another interviewee also specifically mentioned academics who are on the committees, saying the academics "have high ideals but sometimes they can't work at ground level to produce a standard; you cannot set the bar too high because it doesn't work'(IV9).

\section{Awareness of Standards}

As mentioned above, there was widespread acknowledgement among the interviewees of the need for standards in many areas such as "I thought that a standard that could concisely pull things together was very much needed"(IV2). Similarly IV1 said "People need to have a sense of their role and of what the role of learning and development is and how their individual roles position them within that and ... provide quality in learning and development. That's the role of standards."

However, thematic analysis of the data indicates that all the interviewees felt that, despite this need, there was a lack of communication regarding BSI standards in the area of HR; a typical comment was "I don't know anybody in my field who have heard of it or use it" (IV1). The interviewees were unanimous that this lack of awareness of standards applied in the area of HR in general, not just regarding human resource development in particular. Indeed, despite their involvement in BSI standards in the HR area, most of the interviewees had little or no knowledge of standards in the specific area of human resource development. Consequently after three interviews, the questions in the interview protocol were revised slightly to refer to HR in general.

It also emerged that the lack of awareness was generally felt to be the result of dearth of communication by the bodies which developed the standards, for example, only two interviewees mentioned any BSI effort to communicate its standards. Other interviewees expressed surprise, disappointment and frustration that there was no communication of the 
standards after their efforts to help develop them, for example: “There's a lot of frustration about the lack of promotion [of the standards]"(IV7). Other relevant comments include "BSI, I'm afraid, doesn't do a good marketing job of what it's got... I find the BSI approach very odd. There's lots of good that they do; why would you produce something and not have a good look at the impact that it's had?" (IV1), "I think a good marketing strategy would help - because one of the main problems is [organisations] don't know [an HR standard] exists how would you find it?" (IV5) and "There needs to be a much greater effort to reach out to [organisations]" (IV8).

There was some discussion about the lack of communication and marketing being due to the fact that "it would take a lot of effort to disseminate and highlight the advantages of standards" (IV6), coupled with the lack of any support, particularly monetary, from the UK government. Some people remembered government support for promulgation of Investors in People (IiP) standards, but considered that changes in government and in the national economic situation had led to the current lack of such support.

Some BSI communication of standards was mentioned by interviewees, such as a webinar, a journal article and a factsheet on the CIPD website, although the interviewee who mentioned the latter added "I don't know the number of hits on the website" (IV3). One interviewee said that "The BSI has tried to get into magazines"(IV5), but added that this seemed to have been unsuccessful. However, it was felt that all standards developers, not just BSI, were failing to market their offerings, as shown by comments such as "The standards bodies themselves don't seem to put much effort into marketing" (IV3). Indeed, one interviewee professed that "when I talk to the BSI, they have zero marketing budget... It's strange that an organisation that makes its money from standards, they have no marketing capability for standards"(IV13). This interviewee added to this, suggesting that the BSI's 
attempts at marketing were not well-thought through: "In fact, at the launch of BS76000, just to say how bad they are, the marketing guys did not bring a sample copy!"(IV13).

Some interviewees recommended that the BSI's marketing should include case studies of organisations which had achieved success, such as increased productivity or greater employee satisfaction and engagement, as a result of investing in the BSI standards. Relevant comments included: "get decent profile organisations through to say... 'look at the benefits these guys have achieved"'(IV7). Another interviewee suggested "If BSI or ISO are able to find case studies of organisations implementing standards who have then gone on to be successful, that would be great. These should be included when you buy-encouragement to tell us your story after implementation. Sharing stories can mean sharing values, - how can you best do the job?" (IV8). Another interviewee mentioned "I asked some members of the committee to write about their experience" (IV5), but added that this had not led to anything. Similarly, another interviewee thought that knowing that a large organisation was seen to be using the standard, would encourage other organisations to do so, explaining "if the CIPD carried the [BSI] badge, it would be a loud voice. Or if a university or the Civil Service does it"(IV13). However, the interviewee continued by saying that none of these organisations had implemented the BSI HR standards, despite encouragement to do so.

This highlighted a problem voiced by some interviewees, namely "it's quite difficult to get - from the standards bodies - who has taken them up because it's third parties that have their own customers for that service, and so it's hard to know who has adopted standards unless they make a big song and dance about it"(IV3). This "song and dance” could include "Stamps, badges, logos, things to go on websites; people want them and take pride in getting them and then showing them off'"(IV8), in short, items such as those supplied by the IiP to organisations which attain its standards. This was reinforced by interviewees who referred to organisations which had implemented the BSI standard and which, "wanted 
to demonstrate they were good employers and could badge themselves as good employers valuing their workforce"(IV13) and "the organisations that adopt them are trying to make sure that in one way or another they're differentiating themselves from other organisations"(IV3). Nevertheless, there was general agreement that there was a problem identifying how many organisations, and specifically which ones, have implemented BSI HR standards.

Despite interviewees agreeing that there appeared to be low awareness of BSI HR standards, there was disagreement concerning who should be responsible for publicising the standards. One interviewee suggested that the BSI needed to improve how it ran launch events: "Probably the BSI has to have better free launches, free workshops"(IV9) while another commented that they, the members of the BSI standards committees, "need to go to more events [to publicise the standards]"(IV5). Only one interviewee referred to the BSI's failure to use electronic means to promote its standards: "it's not on the radar at all for being found on social media" (IV1) and only one (other) interviewee suggested using such means to promote it, proposing the use of "all sorts of forums, physical and virtual"(IV11). Some interviewees suggested that there should be UK government funding to support such marketing efforts.

However, another interviewee suggested that "organisations such as the CBI and the IoD, the Federation of Small Businesses ... any sort of stakeholder organisation ... Trade Unions and other interest groups" (IV6) such as the CIPD and Chambers of Commerce, could promote awareness of BSI standards through their members. This interviewee expanded on their thoughts regarding CIPD involvement: "It's not just about the CIPD being involved and talking to their members, but making it part of the accreditation process for universities and their courses"(IV6). Several other interviewees agreed that university (HR) courses should include information about standards so that those going on to work in 
organisations could take this information with them and pass it onto their colleagues. Such comments include "Educational establishment delivering courses could talk about standards"(IV7), "the university could teach more about them" (IV5) and "if universities would tell their students that there are British, American, French, International Standards... so the students know, would be good"(IV3). However, one interviewee was a university lecturer and explained "You have, for example, a course in human resource management but there is no standardisation yet, I would think, because, from the academic point of view, we have not had research into it. I've been reading on it and there's nothing much there, so it's not something that can be covered on the current courses yet"(IV6).

\section{Standards Adoption}

Another reason for lack of impact of BSI standards given by a few interviewees was that they felt that people in the workplace would not even think that there would be standards associated with HR. Indeed interviewees suggested that practitioners would not automatically think of investigating whether the BSI would have such material as the BSI was more commonly associated with scientific and perhaps engineering standards. BSI was also perceived as being too far away from the workplace; comments included: "the truth is nobody thinks 'yes, BSI is my first stop at finding out about this', and then, they go searching on the internet for people who have got something - people they trust, - that's really important" (IV1). Another interviewee, when referring to an organisation which had implemented the BSI standard, commented "I think they just stumbled on it"(IV13), while another said "I think that not knowing that [the HR standards] even exist is a bit of a hindrance"(IV11).

Some interviewees considered that BSI standards were not adopted due to the availability of several non-BSI standards or material which could be used as a standard, from bodies such as IiP, CIPD and the Learning and Performance Institute, as well as some larger organisations, developing their own. One interviewee referred to something developed within 
their own organisation which was freely available to other organisations (as the organisation hoped to make money from it through consultancy fees regarding implementation and use): "It's not a standard in the BSI sense, but it helps organisations get a grip on understanding the changing world of learning and development" (IV1).

Constraints to standards adoption

Although, as previously mentioned, interviewees generally agreed that standards were needed, some considered that organisations themselves were not always aware of this need: "[there was] a lack of understanding in the organisation of the benefits that standards can bring to them"(IV12), "because they already have HR processes set up in their organisation they don't see the need [for standards]"(IV5) and "I suppose [there is] a fiction that organisations can design their own processes without reference to models or frameworks that allow us to reflect on practices or models that have evolved culturally over time"(IV13).

The cost of buying BSI standards was cited by many interviewees as a reason for the standards' lack of impact, with comments such as "there is a lot of concentrating on cost" (IV6) and "being able to buy them [would encourage use of standards]" (IV8). There was also a suggestion "with BSI, if they had a discounted version for all CIPD members, they would have sold more... it is overpriced ..." (IV7). Although another interviewee related being at a BSI standards launch event where "people said 'can we have a look before we buy it?' 'No, but you can buy it with a discount voucher" (IV13) and they still did not buy it. Another observation was that "if you have to pay for something today it's very unlikely that you will [buy it]"(IV1) while another interviewee was emphatic that "it has to be free. Recently (BSI) were supposed to do a workshop on organisational excellence and they cancelled it because there weren’t enough takers, but it was $£ 350$ a seat. That is worth it if you know what you're getting out of it"(IV9). This view that there was a reluctance to buy a BSI standard because of a lack of information regarding the consequences of buying a standard was held by several 
other interviewees with comments including "You need to know there is a pay-off. Businesses are being hit by VAT, taxes, etc. so they don't have money to spend on something they don't know whether it is worth it" (IV8).

Interviewees mentioned that it was not just the price of buying the standard, but the realisation that having bought it, there would need to be considerable investment of time and effort: "it takes a lot of time and effort to go for any standard"(IV3) and "the cost associated with change, not necessarily with the cost associated with purchasing the standard, but the time and effort that it takes to put that in place" (IV12).

Discussion of cost led to mention of how organisational size could affect the likelihood of implementing, or at least buying, BSI standards, with one interviewee considering that there should be support for Small and Medium Enterprises (SMEs) concerning this, perhaps from Chambers of Commerce. Interviewees disagreed about the applicability of BSI standards to SMEs, with one stating: "I don't think that someone who, for example, is in a small or medium company could use the standards, well, perhaps some of the standards, but I think most of them are targeted towards large organisations"(IV6).

However, mostly the interviewees disagreed with this view; another interviewee commenting "A standard can be particularly valuable to SMEs as they can't afford HR staff, lawyers, etc. so the standard gives them guidelines regarding what they can do" (IV8). This was added to by another interviewee: "I like the way that it was written with very small organisations in mind, but is scalable up to large organisations like my current organisation" (IV2) and another asserting "those that have taken up this accreditation are largely SMEs" (IV13). Impact of HR standards

Despite the interviewees agreeing that the BSI HR standards appeared to have had little or no impact so far, several of them considered that it was too early to expect any such impact, but had hopes for more impact of HR standards in the future, with opinions such as 
"in HR, it's all new and it might take a bit of time" (IV5). Other interviewees agreed with this: "I do think it's early days. If you think about how long standards have existed in other areas, I think, in terms of human resources, standards are relatively new. It would take a time for people to understand their existence even" (IV6) and "we need time to get some things to happen sometimes... I'm a firm believer that it's three years in after you've achieved recognition that you really start to benefit from the standard... They need to live it and breathe it and make it work for the business"(IV7). It was also considered that it would take longer than three years for any impact of standards to become apparent: "the lack of awareness of the long term benefits of standards, I think, that has partly to do with the very early stages of parts of standardisation. I think, as far as I'm aware, it's not even 10 years old in this area. I think, looking at other areas of standardisation, it takes years"(IV6). Other interviewees thought that having something less formal than a standard might better suit the needs of the current fast-paced business world, including "(in) the world of standards writing a long list of what you should do isn't going to cut it very well'(IV10) and "maybe we need a different way of getting things less threatening"(IV13).

Despite exressing opinions regarding the lack of widespread knowledge and impact of HR standards so far, interviewees generally agreed that their own working practice was influenced by standards. Typical comments included " [my own professional practice has been influenced] in a range of different ways... [A standard] challenges people to think about how they can develop themselves and to be better at it and that's certainly happened to me"'(IV1) and "I've learned a lot... for my own practice I think that the main things are more about attitude because I want to see what makes sense with the HR standard, ...it's not new but it does concentrate [my mind] a bit, especially in a practical sense, what I need to know more of" (IV11).

\section{Discussion}


This section discusses the limited influence of standards on HRD in practice. The social constructivist stance taken in this paper enables consideration of the contextual conditions and interactions of those involved in this process. This underpins the theorization, advanced in this section, that a disconnect arises from contrasting values of stability and uniformity, which are prioritised by those engaged in standards formation, and commitment to responsiveness, change and development that underpins contemporary HRD practice.

Standards formation involves members of technical committees that are governed by formalised rules and procedures to achieve consensus. In relation to the first research question concerning the effect of contextual conditions on standards formation, the data indicate that sustained involvement in standardisation engenders a 'standards vernacular' amongst participants in the process. Study participants reported a specialist HR background but limited prior knowledge and experience of standards. Involvement in standards formation changed things. The findings suggest that assumptions about consistency and uniformity to represent 'best practice' in HR are generated and reinforced as a feature of involvement in standards formation processes (Dokko et al., 2012). Prolonged engagement with standardisation engenders and sustains meanings and assumptions about the value of practice stability that is associated with organisational excellence theory and features of the HPWS approach to HR which focus on the consistent deployment of 'best practice' HR systems as the basis for organizational performance. Participants in this study recognised that their assumptions are at variance with the norms of HR practitioners in organisational settings. They attributed this 'disconnect' to a lack of endorsement of standards by thought leadership and professional organisations such as CIPD and the Institute of Directors. They further referred to a lack of publicity by BSI to promote standards adoption. Whilst institutional theories are critical of isomorphism, this study indicates an enthusiasm by those involved in standards formation for more pressure to promote adoption of the standards. 
Organisational excellence theory assumes that the benefits of standards, benchmarks, incremental change and continuous improvement will be self-evident (Botzem and Dobusch, 2012; Dokko et al., 2012). However, in relation to the second research question, the analysis indicates that HR standards formation has not thus far been influential for HRD practice. Although the 'good employer' marketing and brand opportunities of standards are evident, the variety of different awards and assessment criteria suggest a fragmentation rather than a harmonisation of meanings associated with 'excellence in HR'. This may be explained by considering the interests, goals or 'stakes' (Dokko et al., 2012) of those involved in HRD. Botzem and Dobusch (2012) argue that, in technical and product design areas, a failure to achieve interoperability and harmonisation in key areas of industrial standards is acknowledged to constitute a real threat of market failure. This means that the stakes are high for those involved in standardisation of technical processes. In the HRD field, by contrast, the stakes are lower. Studies of HRD harmonisation processes in different organisations and sectors confirm that the value of discontinuous, strategic change, flexibility and managerial discretion is prioritised over process harmonisation and standardisation (Lahiff, et al., 2019; Short and Harris, 2017). This study further confirms that HRD assumptions about the priority of flexibility and responsiveness over the values of consistency and uniformity serve to diminish professional interest in, and imperatives for, standardisation.

Taken as a whole, therefore, the analysis indicates the importance of the wider professional context of HRD for explaining the lack of influence of the work of standards developers. This analysis foregrounds a paradox inherent in the HRD field that arises from two seemingly contradictory dimensions: consistency of practices and responsiveness of practices (Chapman, et al., 2018; Fu et al., 2020). These dimensions reflect debates between alternative HPWS explanations of HR (Becker, et al., 1997; Fu, et al., 2015) and the Resource Based View (RBV) that focuses on the development of differential, organizational 
practices to promote 'hard to imitate' capabilities within the organisation (Barney et al., 2001; Clardy, 2008). In response to the second research question, therefore, the study shows that, in spite of the HR professional interests, organisational interests, and personal interests of standards developers, there is limited influence of standards on HRD practice. The analysis identifies a disconnect between the meanings and assumptions of those involved in standards formulation and those who might adopt these standards as a feature of their HRD practice. Involvement in standards formation processes engenders assumptions associated with HPWS, and the context for HRD practice prioritises values of flexibility and differentiation influenced by RBV.

The competing dimensions of differentiation and process consistency that constitute the paradox identified here explains the standards-practice 'disconnect'. Those involved in standards formulation operate in a context which endorses, encourages and reinforces assumptions concerning the priority of best-practice consistency as a basis for operational effectiveness (Brunsson, Rasche, and Seidl, 2012; Swann, 2010). Those engaged in organizational HRD are more likely to value flexibility, differentiation, and change (Anderson, 2017). This disconnect renders standardsation as a feature of HRD practice 'invisible' to most practitioners.

\section{Implications for research}

The analysis presented in this article indicates the power of different stakeholders outside the standard-setting process itself that is consequential for the influence of standards in practice. A lack of agreed standards of practice leaves the HRD field vulnerable to the critique of a lack of specialised competency and issues of standardisation raise important questions for HRD scholars, practitioners, and educators. Such issues may also be relevant to other emerging fields of professional practice such as marketing, information services, and project management. 
Future research into the perspectives of those outside the standards setting community is a priority. Specifically, further research is required into the socially negotiated processes arising from the contradictory yet interrelated pressures for process consistency and differentiation in HRD practice (Schad, Lewis, Raisch, \& Smith, 2016; Smith \& Lewis, 2011). In a context where business continuity and risk mitigation have been foregrounded by issues such as pandemics; cyber security challenges; patterns of migration and global climate change, so further research is also necessary to understand the role and relevance of standards to HRD practice in different national and global contexts. Specific research questions arising from this study include the following:

- What organizational and sector-specific factors encourage or inhibit the achievement of cross-organization inter-operability and process harmonization in the HRD field?

- What are the strategic HRD implications of the consistency / distinctiveness paradox in different economic and organizational contexts?

- What are the HRD implications of pandemics; cyber security challenges; patterns of migration and global climate change for business continuity and risk mitigation?

- What impact does professional education have on HRD practitioners' norms and values and what are the implications for standards and standardization of HRD practices?

- How are HRD assumptions concerning standards and organizational excellence developed and maintained in different national and regional contexts?

\section{Implications for practice}

Emerging processes of standardisation in the HR field have implications for HRD professional identity and practice as well as for curriculum development, pedagogy, and education in the HRD field. One implication for practice is a requirement that practitioners examine where HRD structures and processes could usefully be standardised to enable 
transparent benchmarking as a basis for performance enhancement. Second, to achieve benefit from HRD analytics, practitioners can develop standardized measures to describe and report on the organizational value of HRD and generate evidence of the contribution of HRD to financial and non-financial organizational outcomes in an accessible and transparent way. Third, HRD educators should review the extent to which HRD professional education programmes provide appropriate information about relevant national and international standards. In addition, HRD educators should promote reasoned consideration by students of the priorities in HRD practice for both consistency and responsiveness. Fifth, senior organisational HRD leaders might consider engaging with national and international standardisation bodies to influence standards formation processes and lessen the extent of the practice-standards disconnect.

\section{Conclusion}

Over more than 100 years, consensus-based standard setting by non-governmental organisations has become an established feature of organisational life. Organisation-wide management systems and standards are increasingly prevalent. Standards are emerging for professional and occupational fields such as HRD. However, this study identifies a standardspractice disconnect. It indicates the limitations of standards formulation processes undertaken through voluntary, consensus-based committee processes. It explains these limitations as a feature of different assumptions about the contribution of HRD to organisational effectiveness held by those involved in standards formulation processes and by HRD practitioners in organisational settings. The paper adds to knowledge of standardisation processes by focusing on the socially constructed assumptions that arise through standards development processes. It provides the foundation for a much needed theorisation of the influence of standards formation that explains the standards-practice disconnect. This disconnect is an outcome of contextually located HRD priorities, grounded in the RBV 
approach to HR, which are at variance with the values of process harmonization and HRD best practice that are constructed and sustained through involvement in standards formation processes.

\section{References}

Agoglia, C.P., Doupnik, T.S. and Tsakumis, G.T., (2011), "Principles-based at the front of this file forversus rules-based accounting standards: The influence of standard precision and audit committee strength on financial reporting decisions", The accounting review, Vol. 86 No. 3, pp.747-767.

Alberga, T., Tyson, S. and Parsons, D. (1997), "An Evaluation of the Investors in People Standard.” Human Resource Management Journal, Vol. 7 No. 2, pp.47-60. doi:10.1111/j.1748-8583.1997.tb00281.x.

Anderson, V. A. (2017), "HRD standards and standardization: where now for human resource development?" Human Resource Development International, Vol 20, No. 4, pp. 327 345. doi: 10.1080/13678868.2017.1321872.

Bailey, C., Mankin, D., Kelliher, C. and Garavan, T., (2018). Strategic human resource management. Oxford University Press, Oxford.

Barney, J., Wright, M. and Ketchen Jr, D.J., 2001. The resource-based view of the firm: Ten years after 1991. Journal of management, 27(6), pp.625-641.

Becker, B. E., Huselid, M. A., Pickus, P. S. and Spratt, M. F. (1997), "HR as a source of shareholder value: Research and recommendations", Human Resource Management, Vol, 36, pp. 39-47. doi:10.1002/(SICI)1099-050X

Bell, E., Bryman, A. and Harley B. (2019), Business research methods ( $5^{\text {th }}$ ed), Oxford University Press, Oxford.

Bell, E., Taylor, S. and Thorpe, R.(2002). "A Step in the Right Direction? Investors in People and the Learning Organization." British Journal of Management, Vol.13, No.2, pp.161-171. doi:10.1111/1467-8551.00229.

Bourne, M., Franco-Santos, M., Pavlov, A., Lucianetti, L., Martinez, V., and Mura, M. (2008). "The Impact of the Investors in People Standard on People Management Practices and Firm Performance." Management. Retrieved from http://dspace.lib.cranfield.ac.uk/handle/1826/4305.

Botzem, S., and Dobusch, L. (2012), "Standardization Cycles: A Process Perspective on the Formation and Diffusion of Transnational Standards", Organization Studies Vol 33, No. 5-6, pp. 737-762. doi:10.1177/0170840612443626.

Braun, V. and Clarke, V. (2006), "Using thematic analysis in psychology", Qualitative Research in Psychology, Vol.3 No. 2, pp. 77-101.

British Standards Institute (BSI). (2020).’BSI Standards Development: HCS/1 - Human Capital". Retrieved from https://standardsdevelopment.bsigroup.com/committees/50229635

British Standards Institute (BSI). (2018). "What is a standard?" Retrieved from https://www.bsigroup.com/en-GB/standards/Information-about-standards/what-is-astandard/

British Standards Institute (BSI) (2017a). "BS 76005:2017: Overview", available at https://shop.bsigroup.com/ProductDetail/?pid=000000000030338898

British Standards Institute (BSI) (2017b). "PD 76006:2017: Overview", available at: https://shop.bsigroup.com/ProductDetail/?pid=000000000030350673 
British Standards Institute (BSI) (2017c). "Standards", Retrieved from www.bsigroup.com/en-GB/standards/

British Standards Institute (BSI) (2015). "BS 76000:2015: Overview”, Retrieved from http://shop.bsigroup.com/ProductDetail/?pid=000000000030298954

Brunsson, N., Rasche, A., and Seidl, A. (2012), "The dynamics of standardization: Three perspectives on standards in organization studies", Organization Studies, Vol 33, No. 5-6, p. 613-632. doi:10.1177/0170840612450120.

Cascio, W. F., and Boudreau, J.W. (2014), "Evidence-based management at the bottom of the pyramid: Why human resources standards and research must connect more closely", in Hitt, M.A., Jackson, S.E., Jackson, S.E., Bierman, S.C.L., Shelley, C.E., Wright, D.M., Cascio, W.F. and Boudreau, J.W. (Eds.), The Oxford Handbook of Strategy Implementation Oxford University Press, Oxford, Chapter 12, doi:10.1093/oxfordhb/9780190650230.013.12.

Chapman, E.F., Sisk, F.A., Schatten, J. and Miles, E.W., (2018), "Human resource development and human resource management levers for sustained competitive advantage: Combining isomorphism and differentiation", Journal of Management \& Organization, Vol. 24 No, 4, pp.533-550.

Chartered Institute of Personnel and Development (CIPD). (2016). "The importance of organisation culture to governance", available at: https://www.cipd.co.uk/knowledge/strategy/hr/good-practicereport (accessed 9 February 2017)

Clardy, A. 2008. "Human resource development and the resource-based model of core competencies: methods for diagnosis and assessment". Human Resource Development Review, 7(4), pp.387-407.

Corbett, C. J., and Yeung, A. C. L. (2008), "Special issue on meta-standards in operations management: Cross-disciplinary perspectives", International Journal of Production Economics. doi:10.1016/j.ijpe.2007.02.044.

DiMaggio, P. J. and Powell, W. W. (1991) "Introduction", in DiMaggio, P. J. and Powell,

W. (Eds.) The New Institutionalism and Organizational Analysis,. University of

Chicago Press, Chicago, pp. 1-38.

de Waal, A.A. (2013), "Evergreens of excellence", Journal of Management History, Vol. 19. No. 2, pp. 241-278. doi.org/10.1108/17511341311307408

Dokko, G., Nigam, A. and Rosenkopf, L., (2012), "Keeping steady as she goes: A negotiated order perspective on technological evolution". Organization Studies, Vol. 33 No. 5-6, pp.681-703.

Fu, N., Flood, P.C., Bosak, J., Morris, T. and O'Regan, P., (2015), “How do high performance work systems influence organizational innovation in professional service firms?" Employee Relations, Vol. 37 No. 2, pp.209-231.

Fu, N., Flood, P.C., Rousseau, D.M, and Morris, T. (2020), "Line Managers as Paradox Navigators in HRM Implementation: Balancing Consistency and Individual Responsiveness", Journal of Management, Vol. 46, No.2, pp.203-233.

Gibson, W. J. and Brown, A. (2009), Working with Qualitative Data, Sage, London.

Goetsch, D. L. and Davis, S. B. (2014), Quality Management for Organizational Excellence, Pearson, Upper Saddle River, NJ.

Gioia, D. A., Corley, K. G. and Hamilton, A. L. (2013), "Seeking Qualitative Rigor in Inductive Research: Notes on the Gioia Methodology", Organizational Research Methods, Vol.16 No.1, pp. 15-31. 
Gloster, R., Sumption, F., Higgins, T, and Cox, A. (2010), Perspectives and Performance of Investors in People : A Literature Review. UK Commission for Employment and Skills, London.

Guest, D. E., and Woodrow, C. (2012), "Exploring the boundaries of human resource managers' responsibilities", Journal of Business Ethics Vol. 111, No. 1, pp. 109-119. doi:10.1007/ s10551-012-1438-8.

Heras-Saizarbitoria, I., and Boiral, O. (2013), "ISO 9001 and ISO 14001: Towards a research agenda on management system standards". International Journal of Management Reviews, Vol. 15, No. 1, pp. 47-65. doi:10.1111/j.1468-2370.2012.00334.x.

International Organization for Standardization (ISO). (n.d.). ISO TC/260 - Human Resource Management. Retrieved from https://committee.iso.org/home/tc260

Lahiff, A., Li, J., Unwin, L., Zenner-Höffkes, L. and Pilz, M., (2019), "Industrial Standardisation as a Driver for Cross-national Convergence in Training Processes: Aviation Apprenticeships in England and Germany", European Journal of Training and Development, Vol. 43 No. 7-8, pp. 752-766.

Lofland, J., and Lofland, L.H. (1995), Analyzing Social Settings: A Guide to Qualitative Observation and Analysis (3rd ed.), Wadsworth, Belmont, California.

Mi Dahlgaard-Park, S. and Dahlgaard, J.J., (2007), "Excellence-25 years evolution", Journal of Management History, Vol. 13, No. 4, pp.371-393.

Mulvie, A. (2019), Working with External Quality Standards and Awards: The Strategic Implications for Human Resource and Quality Management, Routledge, Oxford.

Murphy, A., and Garavan, T.N. (2009). "The adoption and diffusion of an NHRD standard: A conceptual framework", Human Resource Development Review, Vol. 8, No. 1, pp. 321. doi:10.1177/1534484308330019.

Polacek, G., D. A. Gianetto, K. Khashanah, and D. Verma. (2012), "On Principles and Rules in Complex Adaptive Systems: A Financial System Case Study," Systems Engineering, Vol. 15 No. 4, pp. 433-447. doi:10.1002/sys.

Ponnert, L. \& Svensson, K. (2016), "Standardisation - the end of professional discretion?” European Journal of Social Work, Vol. 19, No. 3-4, pp. 586-599. doi: 10.1080/13691457.2015.1074551

Rodham, K (1998), "Manager or medic: the role of the occupational health professional", Occupational Medicine, Vol 48 No. 2, pp. 81-84.

Saunders, M., Lewis, P., and Thornhill, A. (2016), Research methods for business student $\left(7^{\text {th }}\right.$ ed.), Pearson Education, Harlow, Essex.

Savin-Baden, M., and Major, C. H. (2013), Qualitative Research: The Essential Guide to Theory and Practice, Routledge, London.

Sayer, A. (1984), Method in Social Science: A Realist Approach, Routledge, London.

Scott, R. (2003), Organizations - Rational, Natural, and Open Systems, Prentice-Hall, London.

Scott, W.R., (2008), "Approaching adulthood: the maturing of institutional theory". Theory and society, Vol. 37 No. 5, pp.427-442. DOI 10.1007/s11186-008-9067-z

Short, T. and Harris, R.M., (2017), "Harmonising training and development across an industry: the case of Australian rail", European Journal of Training and Development, Vol. 41 No. 4, pp.373-387.

Watson, T. J. (2001), In Search of Management Culture, Chaos and Control in Managerial Work (Revised), Thomson Learning, London.

Wong. W., Anderson, V., and Bond, H. (2019) Human Capital Management Standards: A Complete Guide. London: Kogan Page.

Wright, P.M., Dunford, B.B. and Snell, S.A., (2001), "Human resources and the resource based view of the firm", Journal of management, Vol, 27 No. 6, pp.701-721. 
Yates, J., and Murphy, C. (2019), Engineering Rules: Global Standard Setting since 1880, Baltimore: John Hopkins University Press.

Yin, R.K. (2016), Qualitative Research from Start to Finish ( $2^{\text {nd }}$ ed), The Guildford Press, New York. 


\begin{tabular}{|c|c|c|c|c|}
\hline Interviewee & $\begin{array}{l}\text { Time } \\
\text { working } \\
\text { (years) }\end{array}$ & Industries / sectors & $\begin{array}{l}\text { Time working } \\
\text { with } \\
\text { standards(years) }\end{array}$ & $\begin{array}{l}\text { Which standard(s) / } \\
\operatorname{committee}(s) / \\
\operatorname{event}(s)\end{array}$ \\
\hline IV1 & $30+$ & HRD & 24 & $\begin{array}{l}\text { BS76000 } \\
\text { L\&D Committee (non- } \\
\text { BSI) } \\
\text { BSI HCS Committee }\end{array}$ \\
\hline IV2 & 12 & HRD & 2.5 & $\begin{array}{l}\text { BSI PD76006 } \\
\text { BSI HCS Committee }\end{array}$ \\
\hline IV3 & 49 & $\begin{array}{l}\mathrm{HR}-\mathrm{UK} \& \\
\text { international }\end{array}$ & 17 & $\begin{array}{l}\text { ISO TC260 } \\
\text { BS76000 } \\
\text { BS76005 } \\
\text { ISO - Diversity \& } \\
\text { Inclusion } \\
\text { BSI HCS Committee } \\
\text { BSI Publicity event }\end{array}$ \\
\hline IV4 & 32 & $\begin{array}{l}\text { Workforce } \\
\text { planning }\end{array}$ & 2 & $\begin{array}{l}\text { BSI HCS Committee } \\
\text { BSI Workforce } \\
\text { Planning Committee }\end{array}$ \\
\hline IV5 & $10+$ & $\begin{array}{l}\text { HRD; Project } \\
\text { Management }\end{array}$ & 2.5 & $\begin{array}{l}\text { BSI PD76006 } \\
\text { ISO HRM Committee } \\
\text { BSI HCS Committee }\end{array}$ \\
\hline IV6 & 14 & $\begin{array}{l}\text { Academia } \\
\text { (Occupational } \\
\text { Psychology\&HRM) }\end{array}$ & 10 & $\begin{array}{l}\text { BAF1010 } \\
\text { (Psychological Health } \\
\text { standard) } \\
\text { BSI HCS Committee } \\
\text { BSI OHS Committee }\end{array}$ \\
\hline IV7 & 30 & $\begin{array}{l}\text { Management; HR; } \\
\text { Standards } \\
\text { accreditation }\end{array}$ & 18 & $\begin{array}{l}\text { BS76005 } \\
\text { BS3002 Health } \\
\text { \&Welfare } \\
\text { BS76000 } \\
\text { ISO45001 Health \& } \\
\text { Safety } \\
\text { BSI HCS Committee } \\
\text { BSI Publicity event }\end{array}$ \\
\hline IV8 & $12+$ & Journalism (HR) & 6 & $\begin{array}{l}\text { BS76005 } \\
\text { BSI rep for } \\
\text { recruitment \& } \\
\text { sustainability } \\
\text { BSI HCS Committee }\end{array}$ \\
\hline IV9 & 25 & $\begin{array}{l}\text { Law; HR; HRD- } \\
\text { UK \& international }\end{array}$ & 10 & $\begin{array}{l}\text { DS5750 } \\
\text { BS76005 }\end{array}$ \\
\hline
\end{tabular}




\begin{tabular}{|l|l|l|l|l|}
\hline IV10 & 40 & $\begin{array}{l}\text { HR }- \text { UK \& } \\
\text { International }\end{array}$ & 5 & $\begin{array}{l}\text { BSI HCS Committee } \\
\text { BSI Publicity event }\end{array}$ \\
\hline IV11 & $5+$ & HR & 1 & $\begin{array}{l}\text { BSI Learning \& } \\
\text { Development } \\
\text { Committee }\end{array}$ \\
\hline IV12 & 19 & $\begin{array}{l}\text { HR - UK \& } \\
\text { international }\end{array}$ & 2 & $\begin{array}{l}\text { BS76000 } \\
\text { BSI Knowledge } \\
\text { Management standard } \\
\text { BSI HCS Committee }\end{array}$ \\
\hline IV13 & $10+$ & HR & 7 & $\begin{array}{l}\text { BS76000 } \\
\text { BSI HCS Committee } \\
\text { BSI Resource } \\
\text { Management } \\
\text { Committee } \\
\text { BSI Publicity event }\end{array}$ \\
\hline
\end{tabular}

Table 1: Interviewees' work experience and involvement with standards 


\begin{tabular}{|c|c|}
\hline Empirical dimensions & Themes \\
\hline $\begin{array}{l}\text { Interviewee personal / Professional } \\
\text { background }\end{array}$ & \multirow[t]{3}{*}{ Pathways to involvement } \\
\hline Involvement in standards development & \\
\hline Personal interest /motivations & \\
\hline Characteristics of standards & \multirow[t]{2}{*}{ Nature of standards } \\
\hline Forms of standards & \\
\hline Standards development experiences & \multirow[t]{2}{*}{ Standards development } \\
\hline Stakeholder involvement & \\
\hline Publicity about standards & \multirow{3}{*}{ Awareness of standards } \\
\hline Market awareness of standards & \\
\hline Need for standards & \\
\hline $\begin{array}{l}\text { Organisational support for standards } \\
\text { adoption }\end{array}$ & \multirow[t]{3}{*}{ Standards adoption } \\
\hline Reasons for adopting standards & \\
\hline Constraints on adopting standards & \\
\hline Future of standards & \multirow{3}{*}{ Impact of HR standards } \\
\hline The nature of HR practice & \\
\hline Impact on personal practice & \\
\hline
\end{tabular}

Table 2. Thematic map 


\section{Appendix A: Brief overview of BSI standards for HRM}

This brief overview was developed from the following sources: British Standards Institute website - https://www.bsigroup.com/en-GB/ and Wong. W., Anderson, V., and Bond, H. (2019) Human Capital Management Standards: A Complete Guide. London: Kogan Page.

\section{BS 76000:2015 - Human resource - Valuing people - Management system - Requirements and guidance -}

\section{https://shop.bsigroup.com/ProductDetail/?pid=000000000030298954}

This standard represents an 'umbrella' standard from which subsequent standards for specialist areas of HRM may be developed. BS 76000 is referred to as an auditable management systems standard and its structure is consistent with other BSI management system standards. It provides a framework for organizations to value people, for the mutual benefit of both parties. It is built on the premise that people are an organization's biggest asset and should be treated as such - so the organization gets the most out of its staff and employees get the most out of their working life.

The principles on which the standard are based are that:

- People working on behalf of the organization have intrinsic value, in addition to their protections under the law or in regulation, which needs to be respected.

- Stakeholders and their interests are integral to the best interests of the organization.

- Every organization is part of wider society and has a responsibility to respect its social contract as a corporate citizen and operate in a manner that is sustainable.

- A commitment to valuing people who work on behalf of the organization and to meeting the requirements of the standard is made and supported at the highest level.

- Each principle is of equal importance.

The standard indicates that "valuing people" goes beyond the calculation of monetary value and short-term returns on investment. It provides organizations with the means of developing their own objectives, behaviours and measures for embedding strategic, long term thinking about the value of their people into their management systems. 
The structure of the standard, is as follows:

- Introduction

- Scope

- Normative references (to other BSI or ISO standards)

- Key terms and definitions

- Context of the organization

- Leadership

- Planning

- Support

- Operation

- Performance evaluation

- Improvement

BS 76005:2017 Valuing people through diversity and inclusion. Code of practice for organizations - https://shop.bsigroup.com/ProductDetail/?pid=000000000030338898

This standard was developed on the basis of the principles established for BS 76000 (Valuing People) and supports a principled approach to diversity and inclusion in organizations. It was developed as a Code of Practice to provide a framework and recommendations for valuing people through diversity and inclusion. It shows how organizations of any size and sector can develop objectives, policies, practices and behaviours that go beyond compliance with legislation and increase the diversity and inclusion of people in, or engaging with, organizations.

The standard recommends a holistic approach to valuing diversity and inclusion to capture individual difference, life experience, social context and historical, economic and cultural exclusion. This standard also encourages dialogue on these issues with a broad range of stakeholders and indicates an approach to take to recognize, value and embed diversity within organizational operations and relationships with customers/clients, supply chains and communities to promote socially responsible actions .

There are three dimensions to the framework

1. Recommendations for how diversity and inclusion can be valued in each of the three phases through which people and organizations interact, namely: (i) getting into organizations; (ii) staying in organizations; and (iii) moving on. 
2. Recognition that the control and influence over the development of diversity and inclusion is strongest within the organization itself but dialogue on issues of diversity and inclusion between organizations and their customers/clients, supply chains and the particular communities they have links to is necessary to embed diversity and inclusion.

3. Identification of leadership commitment and behaviours necessary to value diversity and inclusion in all organizations. It provides organizations with the means of developing their own objectives, behaviours and measures for capturing the effectiveness of their approach.

The structure of the standards is as follows:

- Introduction

- Scope

- Normative references (to other BSI or ISO standards)

- Key terms and definitions

- Getting in/starting the relationship

- Staying in/continuing the relationship

- Moving on/leaving the relationship

\section{PD 76006:2017 Guide to learning and development: -}

\section{https://shop.bsigroup.com/ProductDetail?pid=000000000030350673}

This document was developed on the basis of the principles established for BS 76000 (Valuing People) and supports a principled approach to learning and development to maximize the value of people in an organization.

The premise of this document is that, in a volatile world, organizations need effective learning and development frameworks if they are to adapt successfully to change and at the same time maximize employee opportunities. This guide supplies useful tools to help tackle organizational learning and development more effectively and sets a benchmark for UK companies to hold their L\&D developments against. The document provides a basis for guidance and recommendations on the planning, supporting and evaluation of organizational learning and development in order to help organizations provide learning and development at both organizational and individual levels.

The document provides: 
- A self-assessment tool allowing companies to do a strengths and weaknesses audit

- A roadmap to help facilitate development

- Ideas on how organizations can implement change

- Benchmarking options that will enable users to quantify outcomes

The document is structured as follows:

- Introduction

- Scope

- Normative references (to other BSI and ISO standards)

- Key terms and definitions

- Individual level learning and development

- Techniques for learning and development

- Organizational level learning and development

- Roles and responsibilities for learning and development

- Assessing and evaluating learning and development 